\section{Nação em guerra, repórteres em luta}

As PESSOAS, de uma forma geral, gastam uma boa parcela do seu tempo procurando um significado para suas existências. Estabelecer um conjunto de objetivos eval ores em nome dosquaissedeveviver elutar é, como sesabe, uma tarefa difícil. Tal meta, no entanto, é extremamente mais complexa quando o que se deve justificar é, não a vida, mas a morte.

A final, onde e como pode se encontrar argumentos capazes de dar sentido a uma vida dedicada à propagação da destruição? Como podem indivíduos enações aceitarem em paz de espírito a idéia de matarem ou serem mortos?

Ideologias detodosostipostêm tentado prover ao longo da história respostas a este dilema proposto pela guerra. Podemos, de fato, encontrar modelos de legitimação de muitas espécies: libertemos a Terra Santa (Cruzados); libertemos os povos rudes da barbárie eignorância (colonialismo); etc. Em outras palavras, amenosqueseconsigaapoio popular à ideologia quejustifica edá sentido àmorte, asua própria ou a deoutros rotulados de inimigos, a guerra coloca, na verdade, mais problemas do que soluções às pessoase às nações. É por causa disso que os mass media tendem, emtemposdeconflito armado, advogarem valores que representam o consenso desconsiderando aqueles que são desviantes, críticos e provocadores.

Falkland/ Malvinas éum bom exemplo desta tendência. Este conflito mostra que quando seestáemguerra, areportagemtornase, na verdade, uma extensão do esforço militar de abater o inimigo. Phillip Knightly, autor de Falkland: how Britania ruled the news ${ }^{1}$ mostra neste artigo que o ministro da Defesa da Inglaterra tinha total controle da imprensanasilhasFalkland/ Malvinas, eque os correspondentes de guerra ingleses concordaram com a censura e o controle oficial

Jacques A. Wainberg

Professor FAMECOS/ PUCRS Doutor em Jornal ismo ECA/ USP imposto ao fluxo de informação. “Ninguém poderia antecipar que correspondentes que tinham feito a cobertura deguerras deoutros povos com excepcional objetividade 
descobriram, ao cobriremsua própriaguerra, queo patriotismo era uma força motora mais poderosa que o profissionalismo", diz Knightly.

O modelo britânico aceito pela imprensa daquele país constituiu-se de controle do acesso ao campo de batalha, exclusão dos correspondentes neutros, censura de seus próprios correspondentes eincentivo propagandístico deapoio a suas forças em nomedo patriotismo. Não podemos esquecer, no entanto, que esta guerra se desenrolou num cenário distante do continente, assim como a invasão norte-americanaà Granada, edurante um período curto de tempo. Sob estas condições, o consenso no front interno foi alcançado e mantido.

Um processo similar de obter o apoio público foi conseguido nos primeiros dias da guerra do Vietnã. A retórica oficial descrevendoa "agressão" norte-vietnamitafoi eficiente, despertando a percepção pública para o tema da ameaça potencial do inimigo. Os conhecidos símbolos chaves do imaginário norte-americano deinteressenacional ed efesa da liberdade provocaram um forte efeito emocional como, de resto, os policymakers de Washington supunham que ocorresse. A imprensa seguiu este paradigma de apoio, disseminando a ideologia, dando sentido à guerra e seus efeitos negativos.

As notícias vindas do sudeste asiático, anteriores à campanha do Tet, no qual forças do Vietnã do N orte atacaram massivamente as tropas dos Estados Unidos, reportavam queem $58 \%$ dos casos os americanos tinham tido a iniciativa das ações (contra 30\% do inimigo). No entanto, diz Daniel C. Hallin, autor de The Uncensored War - The M edia and V ietnam² ${ }^{2}$ diz que a seção de A nál ise de Sistema do Departamento de Defesa estimou queem 1967o Vietcong eo Exército do Vietnã do N ortetinham começado o ti roteio em $90 \%$ das lutas do porte de uma companhia. Em $70 \%$ dos casos as batal has foram descritas pelos relatos jornalísticos como favoráveis aos Estados Unidos.

Erararo encontrar, naqueles anos, qualquer repórter deTV quetivessea ousadia de sugerir que os Estados Unidos tinham qualquer políticageral paraatingir objetivoscivis. Mas ataques contra civis perpetrados pelo inimigo "eram diariamenteinsinuadosserem resultadodeumacal culadapolíticadeterror". Michael Sullivan, autor de Vietnam War: a study in the making of A merican policy ${ }^{3}$ chama esteapoio da opinião pública na década de60 de "uma visão extrovertida do mundo".

Do campo de batal ha os correspondentes das emissoras de TV americana evitavam discutir política. Suas histórias eram sobre americanos em ação. E os soldados, ao intervirem no vídeo, reforçavam o consenso ou a justificativa oficial para a guerra. Eles destacavam a necessidade de se deter os comunistas antes "quetenhamos que combatêlos em São Francisco", denominando a guerra de "a batal ha pela democracia contra a agressão comunista". A televisão era mais uma vez não uma arena para o conflito político, mas, como tinha ocorrido nos cinejornais da Segunda Guerra Mundial, suas cenas fal avam de gente e seu esforço em abater o inimigo.

De acordo com Hallin, "os propósitos políticos foram considerados óbvios para serem demonstrados ea atenção do público foi focada no esforço devencer a guerra" (p.140).

Cerca de $62 \%$ de todos os relatos foram apresentados como vitórias para a América (28\% desucesso para o outrolado). Resumindo, a imprensa americana no Vietnã naqueles dias de consenso serviu como um recurso de luta e sua atuação entendida como uma extensão daguerra. Emdecorrência, proposições sutis eram feitas na cobertura (Hallin, p.142): a guerraéuma empreitada nacional; a guerra era uma tradição dos Estados Unidos; na guerra vencer é o que conta; a guerra é um procedimento racional. Em outras palavras, de acordo com Hallin, "a integração da imprensa no establishment político podia ser considerado tão seguro que o vestígio de controle governamental direto poderia ser suspenso".

Talvez por isso o Sidle Panel, conclave convocado para discutir o comportamento dos mass media no conflito, tenha proposto 
uma política de relacionamento fraterno do exército americano paracomaimprensa. Ressalte-se o fato de que não houve reclamações elamentações pela forma como os jornal istas americanos secomportaram na cobertura da guerra. A final, a imprensa dos Estados Unidos não só tinha estabelecido um conjunto voluntário de normas de comportamento ${ }^{4}$, evitando assimacensura oficial, mastambém apoiava-seem grandeparteem fontesoficiais para seus relatos. Somente $20 \%$ de todas as imagens feitas antes da ofensiva Tet mostrou combate real e somente $24 \%$ mostrou breves cenas de feridos ou mortos. Uma norma da rede TV CBS, por exemplo, era muito clara: cautela ao mostrar vítimas e soldados em estado de choque.

Hallin, neste livro, defendeu a idéia, agora tornada popular, de que a imprensa não fez os Estados Unidosperderema guerra do Vietnã. Afinal, não se pode esquecer de quea seleção deimagens eedição constróem o significado do que as audiências vêem e ouvem. Na realidade, as pessoas tendem a ver o que se diz que elas estão vendo. N este sentido, não se pode também esquecer quea TV émais ideologicamente orientada do que a mídia impressa equea TV raramenteabandona a esfera do consenso, reforçando quase sempre crenças e atitudes.

Este foi o caso no conflito das ilhas Malvinas/ Falkland, com a cobertura censurada; e este foi o caso no Vietnã, onde em somente quatro ocasiões as autorizações de jornalistas "indisciplinados" foram cassadas. Istolevaàconclusão dequea retirada/ derrota americana no Vietnã teve outras causas.

Sabe-se que em 1971, 72\% dos cidadãos americanos escolheram a retirada. A opinião pública não tinha mais a popular "visão extrovertida do mundo". Em 1974, 66\% declarou queo Vietnãfoi umerro. O tema eraagora controverso. A imprensa podia e devia refletir estenovo clima de dúvidas sobreos alegadossímbolos-chavesquejustificavamaintervenção americana. Tal fato permitiu a imprensa, em muitas circunstâncias, tornar-se outra vez um investigador independenteque supervisiona e denuncia o abuso do poder.
“Em 1967 as declarações oficiais sobrea guerra ou imagens positivas do papel americano fluiram através dos portões do jornalismo livremente. Imagens de americanos destruindo as casas de camponeses vietnamitas tinham queser cuidadosamente examinados antes que fossem autorizados a passar", diz Hallin. Este já tinha sido o caso em 1965 quando Morley Safer, um repórter da CBS, levou ao público norte-americano cenas que se tornaram um marco na cobertura da guerra.

Tais cenas mostravam mariners queimando o vilarejo deCamNe. "Seránecessário mais do que promessas presidenciais para convencê-lo (ao campesino) de que estamos do seu lado", disseSafer na reportagem. Este chocanterelato eraincomumnadécadade60. Masna de1970, apósa ofensiva Tet, o público acostumou-se com as histórias de vítimas civiscausadaspor açãoamericana, corrupção no regimedo Vietnãdo Sul e, principal mente, a frustração delutar aqueletipo deguerra de atrito ou de pequenas unidades.

A sociedade americana assim como os políticos dos Estados Unidos deram-seconta dequenão sepodelutar uma guerralimitada contra um inimigo para quem a guerra não é limitada. Esteera um conflito planejado para ser contido devido a várias causas. Desdeseu início, devido a necessidade de se obter o apoio da opinião pública. O porte da intervenção americana foi limitado assim como a expectativa de sua duração.

No entanto, ficou pouco a pouco evidente de quea abrangência do conflito tinha ido além do nível do que os detentores do poder de decisão desejavam. Não era mais tão claro nem para o soldado nem para sua família que tipo de interesse nacional estava sendo defendido. Ficou difícil descrever um cenário no qual o espectador decobre facilmente quem é o mocinho e quem é o bandido dahistória. N ão havia qual quer ação decisivaefatal capaz dedar, numcurto espaço detempo, tantoavitóriacomo ofim daguerra. A imprensa refletia esta mudança de clima e depois deheróico período dadécada de 1960 “a televisão reportava periodicamente 
histórias críticas muito diferentes do que qualquer americano tinha encontrado na reportagem deguerrasanteriores", deacordo com Hallin.

Os políticos estavem desgostosos com os militares que eram incapazes de lhes dar uma vitória decisiva. A burocracia de Washington estavasob pressão eaopinião públi$\mathrm{ca}$, como uminstrumento deguerra, começou a agir diferentemente do ocorrido na experiência americana da Segunda Guerra Mundial na qual todos estavam envolvidos. Mesmo naguerra daCoréiaa opinião pública retirou seu apoio, apesar do fato da TV estar ainda em sua infância e a censura imposta.

A missão dequal quer exército é bater o inimigo. Agora se sabeque isso épossível só quandotal comportamento ocorrecomaaprovação da retaguarda, ou seja, o povo que sustenta o soldado no front. Quando isso não ocorre, a imprensa refletee multiplica o mau humor do front interno. Foi esta mudança de humor, enão a imprensa, quevenceu o exército norte-americano. Exatamente, por isso, logo após a guerra, o recrutamento obrigatório foi suspenso; o exército norte-americano profissional izou-se; um comportamento discreto do soldado americano foi obedecido nosanos dedicadosàrecuperação psicológica e de imagem da era Carter e Reagan; e consenso significativo pareceser agora requisito indispensável para assegurar a vitória do exército.

A rota para uma identidade pós-Vietnã tem sido pesarosa edifícil para o exército dos Estados Unidos. Trajetória de reconstrução deimagemfoi seguidalogo apósaguerra por Carter esuapolítica dedireitos humanos. Seu sucessor, no entanto, bateu na tecla da recuperação da auto-estima militar e do papel de potência armada. Sua intenção evidente era resgatar a segurança dos velhos tempos. N essse sentido, a invasão de Granada foi um laboratório experimental desta nova/ velha era, uma "operação" destinada a medir a reação da opinião pública e o clima que se formaria no front interno em torno dos novos/ velhos mitos.

O espectro da ausência de mitos confiáveis e o conseqüente renascimento da auto-estima da nação-império, como tentado por Reagan, pareceram a muitos uma balela. A discreta atuação do exército americano até as recentes guerra do Golfo e da invasão do Panamá foi a resposta dos militares a esta falta de confiança e a consciência de nãoretorno ao imaginário da potência imperial.

Falkland/ Malvinas e Granada não se constituiramnosmelhores dosexemplospara se explorar o relacionamento do exército e a imprensa em tempo de guerra. De qualquer forma, ambosos conflitos mostramcomo estas duas culturas (Imprensa e Exército) tornamse uma quando o consenso e comprometimento do público são al cançados. Mesmo em países livres, sem qual quer censura imposta, como ocorreu no Vietnã, a imprensa tendea jogar o jogo do Exército quando éisso o queo povonaretaguardaexige. Ossoldadossabem que a política, e não a imprensa, é que pode ferir demorteo poder defogo desuas tropas.

Em tempos de paz o exército dos Estados Unidos é tratado pela imprensa daquele país como uma imensa máquina burocrática queemprega 700 mil homens servindo em 18 divisões, seis delas localizadas no exterior, gastando 80 bilhões de dólares e, como tal, teoricamente, requer al guma, mas não obsessiva, atividade desupervisão dos repórteres. E o dilemadebusca desentido não pareceser o tema central deexércitos em tempos depaz já que não colocam sérias questões nem ao público nem aos críticos mordazes da mídia impressa e/ ou eletrônica.

Depois do Vietnã este empregador (o Exército dosEstadosUnidos) tem-secomportado deacordo com as leis do mercado: oferece uma carreira, um emprego, um salário e um status. Soldados são soldados por livree espontânea vontade, e isso confere com o gosto do público e, por conseqüência, com a da imprensa.

O que resta ser visto é como a opinião pública americana está reconstruindo o sentido devida do papel deseu país no mundo. A questão colocada pela guerra do Vietnã e agora pelo conflito no Golfo é: o quesignifica ser poderoso? Estáclaro quenão seprecisater 
grande território, grande exército ou enorme população para uma nação ser respeitada, como é o caso do Japão. Talvez nos tempos modernos, não só exércitos mas, principalmente, desenvolvimento econômico confira status.

A recente experiência da Guerra do Golfoéum rico exemploquepropiciamatéria prima para reflexões como a do tipo queaqui se propôs. O que se pode registrar tentativamente no que diz respeito ao tópico central desteensaio, ou seja, orelacionamento de duas culturas radicalmente distintas, o Exército e a Imprensa, no contexto de uma situação de stress absoluto como a guerra, é que pouco jornalismo investigativo foi feito por parte dos correspondentes do ocidente, as fontes oficiais foram mais uma vez privilegiadas, o exército impôs, àsemelhança de Granada, controles de movimento aos repórteres, o engajamento da cobertura foi dirigido para mostrar, como na Segunda Guerra Mundial e no conflito da Coréia, o soldado em ação; o debate político cessou com o início das hostilidades, o engajamento do front interno foi obtido de forma massiva (o percentual de opinião pública que apoiou o presidentedos Estados Unidos no início do conflito no Golfo foi praticamenteidêntico ao proporcionado a Roosevelt após o ataque a Pearl Harbour), o período de duração da guerra, por sorte, foi curto, evitando o desgaste e a crise simbólica debilitadora das batalhas longas e aparentemente intermináveis.

As razões pragmáticas da intervenção do Ocidente em luta pelo controle dos mananciais de petróleo foram adequadamente acobertados pelos motivos excitadores de adesão, entre eles, o fim à expansão de um ditador bárbaro, o resgate da cidadania kwaitiana, a ajudaanaçõesamigasefraternas ameaçadas ealuta pelaliberdade. A pelosaos motivoseao contexto daSegundaGuerra, tão intensamente tratados pela propaganda do ocidente foram facilmente resgatados e utilizados com eficiência.

Diabolizou-se o inimigo e glorificou-se os novos Aliados vindos de todos os quadrantes para lutarem pelos ideais que uniram os da década de 1940. A cima detudo, para o público eexército dos EstadosUnidos, a experiência permitiu a catarsetalvez definitiva dos traumas inibidores da debacle do Vietnã. As forças armadas dos Estados Unidos resgataram sua dignidade, com um número mínimo debaixas, enquantoaimprensa concordava em comportar-se, mais uma vez, em nomeda pátria, com um código deguerra na mão: poucas imagens de vítimas civis ede soldados mortos e feridos.

Osoficiaisamericanos decomunicação, treinados na nova ótica pós-Vietnã, sabiam identificar com clareza o seu dilema. Ou seja, de um lado, reconhecer o impacto "balístico" da palavra dirigida ao civil desdeo front e, do outro, tratar dedomar a presunçãojornalística de vasculhar, em nome da liberdade de imprensa, informação sobre tudo e sobretodos.

O que se viu, e esta história certamente começa a ser contada, foi uma proeza de engenharia social. O sucesso talvez tenha decorrido deumaliado inesperado, o próprio inimigo, cuja ação e discurso alimentou a psique ocidental de temores, ódios, preconceitos, além dos seus interesses geopolíticos. Comumcal deirão como essefermentando no front interno o soldado obteve o que precisava: o apoio de suas próprias famílias. Foi o que faltou no Vietnã!

A imprensa dos Estados Unidos, com o passar dos anos, liberta-se, pois, da acusação de derrotar o exército de seu próprio país no Vietnã. Como se pretendeu mostrar, as duas culturas, em condições de stress, dão-se as mãos. A presunção do repórter cedeao apelo da pátria, da liberdade, da democracia, do interesse, e do bem estar psíquico das famílias.

N inguém vive sem tais ou outros motivos semelhantes. É como pedir ao repórter vasculhar a verdade em nome da comunidadequando esta mesma comunidadenão quer outra coisa do que coesão em torno do ente querido queluta, acima de tudo, para sobreviver no campo de luta . 


\section{Notas}

1 KNIGHTLY, Phillip. Falkland: how Britanic ruled the news.

2 HALLIN, Daniel $C$. The uncensored war - The media and Vietnam. New York, Oxford Press University, 1986.

3 SULLIVAN, Michael P. Vietnam War: a study in the making of American Policy. University of Kentucky Press, 1985.

4 Os veículos, entre outras normas, concordaram em não divulgar movimentos de tropas e números de feridos emortos. 